\title{
Operation Principles of Quasi Z-Source Modular Multilevel Converters
}

\author{
Fatma A. Khera ${ }^{1,2} \quad$ Christian Klumpner ${ }^{1} \quad$ Pat W Wheeler ${ }^{1}$ \\ ${ }^{1}$ Power Electronics, Machines and Control Research Group, \\ University of Nottingham, Nottingham, UK \\ ${ }^{2}$ Electrical Power and Machines Engineering Department, Tanta University, Egypt \\ E-mail: fatma.khera@nottingham.ac.uk, klumpner@ieee.org
}

\begin{abstract}
This paper proposes the integration of a quasi Zsource network with a modular multilevel converter (MMC) to provide voltage boost capability. The proposed quasi-Z-source MMC uses two symmetrical networks of inductors and capacitors connected between the two terminals of the DC-input source and the MMC DC-link. The operation principle, a suitable PWM method and a capacitor voltage balance strategy are proposed. The limitations of the proposed circuit are identified and a solution of using bidirectional quasi-Z-sourcenetworks is identified. The simulation results presented in the paper verify the operation and the performance of the proposed topology.
\end{abstract}

Keywords-quasi Z-source, modular multilevel converter, Bidirectional.

\section{INTRODUCTION}

The development of medium voltage DC (MVDC) grids has received considerable attention in recent research papers $[1,2]$. The implementation of MVDC distribution grids as an alternative to AC grids has advantages in terms of grid system efficiency [3], reliability and overall operating costs [2]. As a result of the emergence of MVDC grid, voltage source multilevel inverters (MLIs) are needed to interface the different parts of the grid. MLIs are preferred due to their attractive features compared to two-level voltage source inverters (VSIs) [4]. Among of multilevel topologies, the MMC has gained increasing acceptance in both medium and high voltage applications. The modular multilevel converter (MMC) is a relatively new topology which has been proposed by Marquardt et al in 2002 [5]. It is able to overcome many of the difficulties of other multilevel converter topologies and provides features such as design modularity, voltage and power scalability, failure management capability and better harmonic performance [6]. As well as being considered for high voltage applications such as high voltage DC (HVDC) [7], the MMC is now being considered for MVDC applications as well [8]. In order to maximise the functionality, it can be expected that MVDC grids will be required to supply AC loads with a voltage higher than their corresponding DC voltages. However, similar to conventional voltage source inverters, the MMC has no voltage boost capability so the peak output voltage is limited by the DC link voltage. In order to be able to achieve a MMC based circuit with both voltage buck and boost capabilities, this paper proposes that the impedance network concept [9] to be integrated with the basic MMC topology. Among impedance network topologies, quasi Z-source (qZS) network has attractive advantages, for example drawing a continuous input current and therefore lowering the source current stress as well as having a reduced capacitor voltage rating requirement [10]. Therefore, qZS network can be suitable for various applications such as photovoltaic (PV) system. Despite the various features for qZS and MMC, there is a gap in literature regarding their possible integration. This integration is proposed in this paper, the resulting converter being referred to as the quasi Z-source modular multilevel converter (qZS-MMC). This converter can work in both buck and boost modes.

This paper gives a detailed circuit analysis of the proposed qZS-MMC with a focus on the operating principles and converter performance. The equivalent circuit of the qZSMMC with the implemented sinusoidal pulse width modulation (SPWM) boosting scheme is presented. Then, the MMC capacitor balancing strategy is introduced and the operational limits and potential disadvantages of the proposed topology are found. This paper also suggests some modifications to the proposed topology, that will result in a bidirectional quasi Zsource modular multilevel converter (BqZS-MMC), that will improve the performance of the converter. Finally, the operation and analysis of the proposed converter is validated using simulation results.

\section{OPERATION PRINCIPLES OF THE MODULAR MULTILEVEL CONVERTER}

The topology of a single-phase three-level modular multilevel converter (MMC) is shown in Fig. 1. The MMC leg consists of two arms, the upper and the lower arms. Each arm consists of series-connected sub-modules (SMs), and an arm inductor $\left(L_{o}\right)$. Each sub-module has a half-bridge inverter configuration with one DC capacitor charged at average voltage $V_{c}$. The two switches $\left(S_{a}\right.$, and $\left.S_{a x}\right)$ in SM are controlled by complementary gating signals. When $S_{a}$ is on, SM capacitor is bypassed and $\mathrm{SM}$ terminal voltage is zero. If $S_{a}$ is off, SM terminals voltage is $V_{c}$ and $\mathrm{SM}$ capacitor is inserted into the circuit. At any instant, for the topology shown in Fig. 1, four out of eight switches must be turned on, two from each arm. Each submodule capacitor is charged by a fraction of dc bus voltage $E / N$ where $N$ is the number of sub- modules per arm. Therefore, the output voltage $\left(V_{a o}\right)$ swings between $-E / 2$ and $E / 2$ and each arm should aim to produce the output voltage potential. The modulation scheme for generating these states will be explained in section IV. The two arm currents $\left(i_{p a}\right.$ and $i_{n a}$ ) are not discontinuous because the load current $i_{a}$ is shared simultaneously by two arms. Assuming the direction of $i_{p a}$ and 


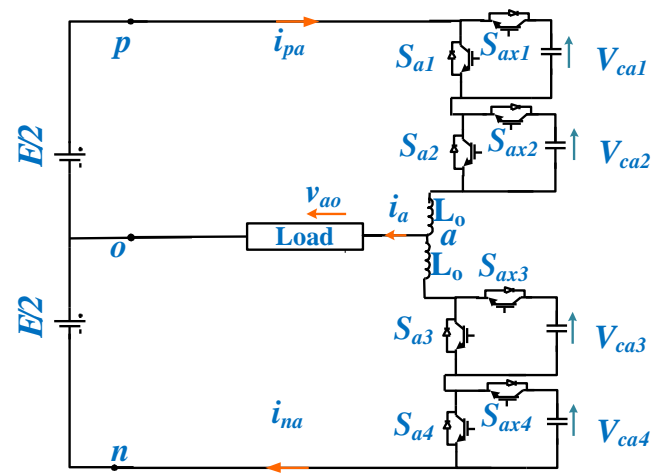

Fig. 1: Typical two-cell single-phase three-level MMC

$i_{n a}$ as shown in Fig. 1, The load and arm currents can be expressed by:

$$
i_{a}=i_{p a}-i_{n a} ; i_{p a}=i_{a} / 2+i_{c i r} ; i_{n a}=-i_{a} / 2+i_{c i r}
$$

where $i_{c i r}$ is the circulating current which is responsible for equal charging and discharging of all sub-modules capacitors so each of them has equal average DC voltage. This current contains DC and AC components which flows through the two arms and has no influence on the load currents. The circulating current can be expressed by:

$$
i_{c i r}=i_{2 f}+I_{d c}
$$

where $I_{d c}$ is the DC component which is responsible for transferring real active power from the supply to the load. The AC component $i_{2 f}$ is a result of the switching process. It is reported that these AC components contain even order harmonics, with the second order one is the most significant one. Therefore, in this research, the MMC circuit can be simply represented by a continuous DC current source $I_{d c}$, and two AC current sources, one accounting for the fundamental load component $i_{a}$ and other one for the second order harmonic component $\left(i_{2 f}\right)$ as shown in Fig. 2.

\section{THE PROPOSED QZ-SOURCE MMC AND ITS ANALYTICAL MODEL}

The simplified representation of the proposed quasi Z-Source modular multilevel converter (qZS-MMC) is shown in Fig. 2. The circuit consists of two identical qZS networks which are inserted between the DC source and the MMC leg. Assuming a split DC-link is typically needed from the DC-source to connect the half bridge inverter to an AC load, then the two networks need to have a midpoint node between the two capacitors $C_{u l}, C_{n l}$ that can be used as a reference point for the output voltage. The operating principle of the qZS network [10] requires the introduction of $\mathrm{p} / \mathrm{n}$ short circuit at its terminals in order to increase the energy in the qZS network inductors that is later transferred in the qZS network capacitors and finally this extra voltage provides the voltage boosting capability. The qZS network operates in two modes, shootthrough (ST) mode and non-shoot-through (NST) mode during the switching cycle $T$ equals $1 / f_{s}$ where $f_{s}$ is the switching frequency. The steady state analysis of qZS networks in each mode is carried out assuming that: $C_{u l}=C_{n 1}, C_{u 2}=C_{n 2}$ and $L_{u l}=L_{n l}=L_{u 2}=L_{n 2}$. In the following analysis, assuming the voltages and the currents have their average value, the capacitor voltages and inductor currents are given by:

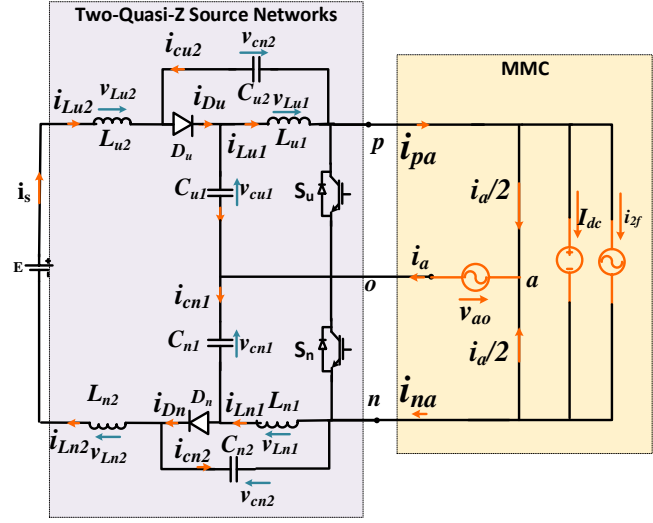

Fig. 2: The proposed quasi Z-Source MMC (qZS-MMC)

$$
\begin{gathered}
v_{c u 1}=v_{c n 1}=V_{c l} ; v_{c u 2}=v_{c n 2}=V_{c 2} \\
i_{L u 2}=i_{L u 1}=i_{L n 2}=i_{L n 1}=I_{L}
\end{gathered}
$$

In this study, the shoot-through intervals are inserted into the circuit during the zero states of the output voltage levels. For simplicity, two switches $S_{u}$ and $S_{n}$ are included at the two networks end-terminals to provide ST current path to the DClink midpoint, but the ST functionality can be implemented also by the MSs The performance of the two qZS networks in each mode can be analysed as follows:

\section{A. Shoot-through mode (ST)}

This state begins when the one or/and two networks terminals are shorted by turning on $S_{u}$ or/and $S_{n}$ which forces $D_{u}$ and $D_{n}$ to become reverse biased and therefore replaced by an open circuit. In this paper, shoot-through intervals are inserted during zero output voltage, so all SMs in MMC side need to be bypassed. In this mode, the stored energy in the qZS-capacitors begins to transfer to inductors. So inductor currents increase and capacitor voltages decrease. The equations for this equivalent circuit can be written according to $[10,11]$ as follows:

$$
v_{L u 1}=v_{L n 1}=V_{c 1} ; v_{L u 2}=v_{L n 2}=E / 2+V_{c 2} ; v_{p n}=0
$$

The network capacitor currents can be obtained as follows:

$$
i_{c u 2}=i_{c u 1}=i_{c n 2}=i_{c n 1}=-I_{L}
$$

\section{B. Non-Shoot-through mode (NST)}

In this mode, $D_{u}$ and $D_{n}$ are forward biased, the stored energy of qZS-networks inductors begins to transfer to the load and $\mathrm{C}_{\mathrm{u} 1}, \mathrm{C}_{\mathrm{u} 2}, \mathrm{C}_{\mathrm{n} 1}$ and $\mathrm{C}_{\mathrm{u} 2}$ begin to charge. So, the capacitor voltages increase and inductor currents decrease. Expressions for this equivalent circuit can be written as:

$$
\begin{aligned}
& v_{L u l}=v_{L n 1}=-V_{c 2} ; v_{L u 2}=v_{L n 2}=E / 2-V_{c 2} \\
& v_{p o}=v_{o n}=V_{c 1}+V_{c 2} ; v_{p n}=2\left(V_{c 1}+V_{c 2}\right)
\end{aligned}
$$

The network capacitor currents can be obtained as follows:

$$
i_{c u 1}=i_{c u 2}=I_{L}-i_{p a} \quad ; i_{c n 1}=i_{c n 2}=I_{L}-i_{n a}
$$

The qZS networks diode currents relations as a function of their corresponding arm current are given as follow:

$$
i_{D u}=2 I_{L}-i_{p a} ; i_{D n}=2 I_{L}-i_{n a}
$$

The converter switching period $T$ can be expressed by $T=T_{s h}+T_{n s t}$, where $T_{s h}$ is the shoot-through interval, and $T_{n s h}$ is the non-shoot-through interval. 
Let $d_{s h}$ and $d_{n s t}$ be the ST and NST duty ratios respectively defined by:

$$
d_{s h}=T_{s h} / T ; \quad d_{n s h}=T_{n s h} / T
$$

At steady state, the average value of the inductor voltages over one switching period equals zero. Therefore, the average capacitors voltages $\left(V_{c l}\right.$ and $\left.V_{c 2}\right)$ are given by:

$V_{c l}=\left(1-d_{s h}\right) /\left(1-2 d_{s h}\right) \times E / 2 ; V_{c 2}=d_{s h} /\left(1-2 d_{s h}\right) \times E / 2$

Substituting from (10) into (6), and assuming that $v_{p n}, v_{p o}$ and $v_{o n}$ are constant and equal to their average value $V_{p n}, V_{p o}$ and $V_{o n}$ during NST intervals, the dc-link voltage during NST mode and the peak value of the fundamental output phase voltage $\left(V_{m}\right)$ are derived:

$$
\begin{gathered}
V_{p n}=2 V_{p o}=2 V_{o n}=B \times E \\
V_{m}=M \times V_{p n} / 2=M \times B \times E / 2
\end{gathered}
$$

where $M$ is the converter modulation index and $B$ is the voltage boost factor which is given by:

$$
B=1 /\left(1-2 d_{s h}\right)
$$

The possible operation range of $d_{s h}$ is from zero to 0.5 . Therefore, $B$ varies from 1.0 to infinity. When setting $d_{s h}=0$, the converter works in buck mode. According to (8), it is noted that the diodes are forward bias during non-shoot-through intervals when upper or lower arms currents are smaller than double of average inductor current. Otherwise, the diodes will be reverse biased. The boundary where the diodes state change naturally from forward to reverse bias and the implication in the operation of the circuit and its performance are investigated thoroughly in section $\mathrm{V}$.

\section{MODULATION SCHEME AND MMC CAPACITORS VOLTAGE BALANCING}

\section{A. Modulation scheme}

To synthesize a three-level voltage waveform at the converter AC-side, phase opposition disposition SPWM (PODSPWM) is used in this study to control the qZS-MMC. For the three-level MMC, two triangular carriers $\left(c_{1}\right.$ and $\left.c_{2}\right)$ with the same frequency and amplitude are required as indicated in Fig. 3 . Each carrier is responsible for producing the gating signals of two complementary cells (one from upper and one from lower). A reference modulating waveform is compared against the two carriers to define which leg-switches are conducting. If the reference waveform is higher (lower) than the two carriers, positive (negative) voltage levels at load terminals are produced respectively, otherwise, zero voltage level is generated. A zero voltage level can be produced by any of the four switching states which are named redundant states that can be selected to guarantee voltage balancing among SMs capacitors [10]. Shoot-through switches $S_{u}$ and $S_{n}$ are controlled by employing another modulating signal $V_{s h}$ which has a positive DC value equal to peak value of the reference modulating waveform and intersects with the upper triangular carrier $C_{2}$ as shown in Fig. 3. The ST intervals occur only when carrier signal $C_{2}$ is greater than $V_{s h}$ which means that all sub-modules are bypassed. The relation between modulation index $M$ and $d_{s h}$ is given by:

$$
M=1-d_{s h}
$$

As mentioned earlier, $d_{s h}$ is in the range between 0 and 0.5 , therefore, $M$ operation range is limited from 0.5 to 1 .

\section{B. Capacitor voltage balance}

The MMC requires a voltage balancing strategy to balance and keep the sub-modules capacitor voltages at their desired average values. The implementation of balancing strategies depends on the presence of the redundant states. For the threelevel MMC, the redundant states are four which only synthesize the zero voltage level. The redundant switching state with the strongest effect in facilitating voltage balancing is always selected. The MMC arm capacitors balancing can be achieved by different strategies [11]. The most widely used balancing strategy is based on the sorting method [6] which is summarized in four steps as follows: 1) Measure and sort the upper and lower capacitor voltages; 2) From modulation scheme, determine the number of inserted cells $\left(n_{p}\right.$ and $\left.n_{n}\right)$ from upper and lower arms respectively; 3 ) If the upper (lower) arm current is positive, choosing the $n_{p}\left(n_{n}\right)$ cells with lower voltage to be inserted. Therefore, the corresponding cell capacitor is charged and its voltage increases; 4) If the upper (lower) arm current is negative, choosing the $n_{p}\left(n_{n}\right)$ cell with higher voltage to be inserted. Therefore, the corresponding cell capacitor is charged and its voltage decreases.

\section{OPERATING MARGINS OF QZS-MMC}

In this study conducted, the values of inductances and capacitances are assumed to be sufficiently large so that the inductor currents and capacitor voltages have negligible ripple. As stated previously, during ST mode, the diodes will always become reverse biased. However, during NST mode, the two diodes $D_{u}$ and $D_{n}$ are forward biased if the following conditions are met, otherwise the diodes will be reverse bias.

$$
2 I_{L}>i_{p a} ; 2 I_{L}>i_{n a}
$$

According to (14), if $i_{p a}\left(i_{n a}\right)$ becomes higher than twice the inductor current $2 I_{L}, D_{u}\left(D_{n}\right)$ will become reverse biased and $i_{p a}$ $\left(i_{n a}\right)$ will be equal $\mathrm{i}_{\mathrm{Lu} 1}+\mathrm{i}_{\mathrm{Lu} 2}\left(\mathrm{i}_{\mathrm{Ln} 1}+\mathrm{i}_{\mathrm{Ln} 2}\right)$. As a result, the upper (lower) dc-link voltage $V_{p o}\left(V_{o n}\right)$ given by (11) will drop by $2 V_{c 2}$, affecting the operation of the qZS-MMC. For simplicity, in (1), by setting the second order harmonic to zero, the maximum values of the upper $\left(I_{p a}\right)$

and lower $\left(I_{n a}\right)$ arms currents can be expressed as a function of the peak value of load current $I_{a}$ and DC component $I_{d c}$ by:

$$
\mathrm{I}_{\mathrm{na}}=I_{p a}=I_{d c}+I_{a} / 2
$$

A maximum value of the load current can be calculated from power balance equation, which is given by:

$$
I_{a m}=2 E I_{L} / V_{m} \cos \theta
$$

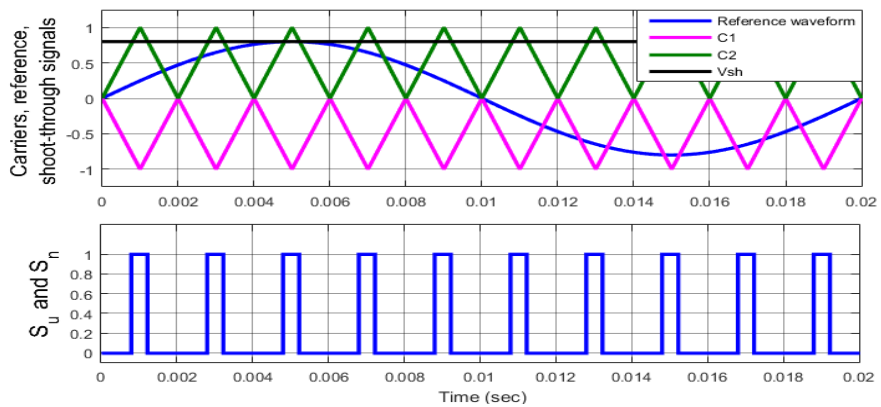

Fig. 3: Generation of ST signals based on POD-SPWM for $S_{u}$ and $S_{n}$ 
where $\cos \theta$ is load power factor (PF). The average value of capacitors' currents during switching period $T$ equals zero. So by using (5) and (7), $I_{d c}$ can be expressed by:

$$
I_{d c}=\left(1-2 D_{s h}\right) /\left(1-D_{s h}\right) \times I_{L}
$$

Substituting from (13), (16) and (17) into (15), the peak value of two arms currents is given by:

$$
I_{n a}=I_{p a}=\left(1-2 D_{s h}\right)(1+2 / \cos \theta) /\left(1-D_{s h}\right) \times I_{L}
$$

By comparing (14) with (18), the condition for the diodes to be forward biased during NST intervals is given by:

$$
\left(1-2 D_{s h}\right)(1+2 / \cos \theta) /\left(1-D_{s h}\right)<2
$$

From (13) and (19), the $M$ value is restricted by:

$$
M<0.5+\cos \theta / 4
$$

Equation (20) shows that the allowable modulation index range depends on the $\mathrm{PF}$. At unity $\mathrm{PF}, M$ operation range is $0.5<M<0.75$ and this range reduces gradually by having a more inductive load. The drawbacks caused by this configuration are: i) dropping in overall DC-link voltage during non-shootthrough mode especially at $M>0.75$ at unity $P F$. ii) overcharging of all converter capacitors which may lead to converter elements damage. iii) working only in boost mode, not applicable in buck mode. iv) applicable only with unity and inductive PF. The reasons for these limitations and drawbacks in qZS-MMC are the two uncontrolled diodes $\left(D_{u}\right.$ and $\left.D_{n}\right)$ that have their states dependent on the circuit operating conditions such as, modulation index and load PF. These two diodes play a dominant role in the DC voltage boosting and cannot be removed. The solution to address these drawbacks to the qZSMMC operation is to insert two active switches (IGBT) in antiparallel with diodes as shown in Fig. 4. This novel resulting topology is referred as a bidirectional quasi Z-source MMC (BqZS-MMC) and is investigated in the following section.

\section{NOVEL BIDIRECTIONAL QUASI Z-SOURCE MMC (BQZS-MMC)}

The topology of BqZS-MMC is shown in Fig. 4. The idea of adding two additional controllable switches $\left(T_{n}\right.$ and $\left.T_{u}\right)$ is not only to expand the range of $\mathrm{M}$ and $\mathrm{PF}$ of qZS-MMC during the inversion process, but also to add the possibility of power returning back to the supply during regenerative operation. In this research, the BqZS-MMC is investigated during inversion mode (power flows from DC source to AC load) only. The additional switches can be controlled simultaneously by a gate signal which is a complement to the shoot-through gate signal illustrated in Fig. 3. In order to simplify the analysis of the second proposed topology, the BqZS-MMC circuit can be divided into two parts (upper and lower parts) as shown in Fig. 4. The upper (lower) part circuit may be analysed in two different regions ( $U-1$ and $U-2)$ as shown in Fig. 5 which is depending on the instantaneous values of the upper (lower) arm current and average value of the inductor currents $\left(I_{L}\right)$ as detailed earlier in Section V.

In each region, there are two modes, ST and NST modes. Once more, the ST mode in the two regions is identical to the previous analysis in section III. The difference will appear in the NST mode, where the capacitors charging and discharging will depend on which semiconductor devices $\left(D_{u}, T_{u}, D_{n}\right.$ and $T_{n}$ ) are conducting. However, qZS network inductors are discharging as their stored energy moved into the qZS network capacitors and the load regardless of the operation regions. The following description is carried out on the upper-part and consequently, the lower-part circuit will be similar. The waveforms of the upper arm current and upper-part capacitor voltages over output voltage cycle are shown in Fig. 5. The NST mode in the two operation regions of upper part circuit are described as follow:

a) Upper-region $U-1$ when $2 I_{L}<i_{p a}(t)$ : This region appears when the upper arm current is higher than $2 I_{L}$, as shown in Fig. 5. Therefore, according to (14), $D_{u}$ will become reverse biased. So, $T_{u}$ must be turned on to avoid any drop in dc link voltage caused by discontinuous conduction, as discussed earlier. Upper capacitors $\left(C_{u j}\right)$, where subscript $j$ equals 1 or 2 , are discharged by a rate which can be expressed by:

$$
\mathrm{dv}_{\mathrm{cuj}} / d t=\left(\mathrm{I}_{\mathrm{L}}-\mathrm{i}_{\mathrm{pa}}(\mathrm{t})\right) / \mathrm{C}_{\mathrm{uj}}
$$

b) Upper-region $U-2$ when $2 I_{L}>i_{p a}(t): D_{u}$ is forward biased because $i_{p a}$ is smaller than $2 I_{L}$. If $i_{p a}$ waveform decreases below $2 I_{L}$ but remain higher than $I_{L}$, the upper-part capacitors are discharged by rate which given by (21). Then, once $i_{p a}$ equals $I_{L}$ value at point " $\mathrm{x}$ " as shown in Fig. 5, the upper capacitor voltages reaches their minimum values. After that, the upper arm current decreases below $I_{L}$ value, upper capacitors are charged up. As soon as $i_{p a}$ returns to $I_{L}$ value again at point "y", the upper capacitor voltage are charged to their maximum values.

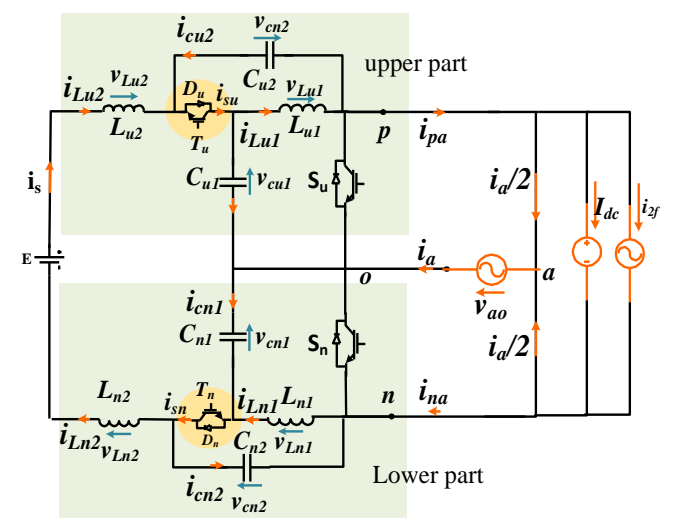

Fig. 4: The proposed topology, bidirectional quasi-Z-Source MMC

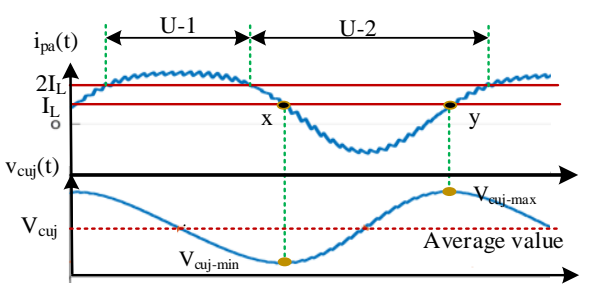

Fig. 5: Upper-part circuit operation regions

\section{SIMULATIOM RESULTS}

To verify the validity of the proposed qZS-MMC and BqZS-MMC, simulation models are implemented in MATLAB/ SIMULINK for the proposed configurations shown in Fig. 2 and Fig. 4. The parameters used in the simulation models are given in Table 1 . The simulation study has been 
carried out using an inductive load with $\mathrm{PF}=0.95$ and considering that all system components and switches are ideal. The simulation results corresponding to the qZS-MMC and BqZS-MMC at different values of modulation index for both buck and boost modes are shown in Fig. 6 to Fig. 8 .

Firstly, the modulation index $M$ is set to 0.7 and consequently the shoot through duty ratio $d_{s h}$ is set at 0.3 according to (13). The two topologies will produce the same response. The reason is that both arm currents are always lower than twice the inductor current, as discussed earlier. According to (20), there is not any current will path through the two switches $\left(T_{u}, T_{n}\right)$ at modulation index lower than 0.74 . Fig. 6a illustrates the upper and lower arm currents and their DC link voltages. It is clear that there is no drop in the MMC DC-link voltage at $M=0.7$. Fig. $6 \mathrm{~b}$ shows the arms capacitor voltages which are charged at their expected average value of $248 \mathrm{~V}$ which is equal to the upper (lower) DC link voltage given by (11). In addition, the qZS-network capacitors' voltages are shown in Fig. 6b. These capacitors are charged at their expected average values $V_{c 1}$ and $V_{c 2}$ which equals $174 \mathrm{~V}$ and $74 \mathrm{~V}$ respectively. Load voltage and current and their harmonic spectrums are shown in Fig. 6c.

The second test is carried out at $M=0.9$ and $d_{s h}=0.1$. As shown in Fig. 7a, it is clear that when the waveforms of both arm currents are higher than twice the inductor current $\left(2 I_{L}\right)$, the upper or lower DC-link voltages will drop. When the two additional switches are connected in antiparallel to the qZSnetwork diodes, the DC-link voltage never drops, as expected in BqZS-MMC topology and this is shown in Fig. 8a. Fig. 7b and Fig. $8 \mathrm{~b}$ show the voltages of the two arms and the qZSnetwork capacitors of the two converters, the qZS-MMC and the BqZS- MMC respectively. The capacitors in qZS-MMC are overcharged where according to (10), the expected average values of network capacitor voltages $V_{c 1}$ and $V_{c 2}$ are $112.5 \mathrm{~V}$ and $12.5 \mathrm{~V}$ respectively. The average resultant network capacitors voltages are $122 \mathrm{~V}$ and $22 \mathrm{~V}$ as shown in Fig. $7 \mathrm{~b}$. In addition, the expected average value of the arms capacitors' voltages is at the peak value of half of the DC-link voltage which equals $125 \mathrm{~V}$ as predicted by (11). The average value of the arm capacitor voltages is $135 \mathrm{~V}$ as shown in Fig. 7b. Fig. 8 shows the same set of results but for the BqZS-MMC. It can be seen that all capacitor voltages are at their expected values as

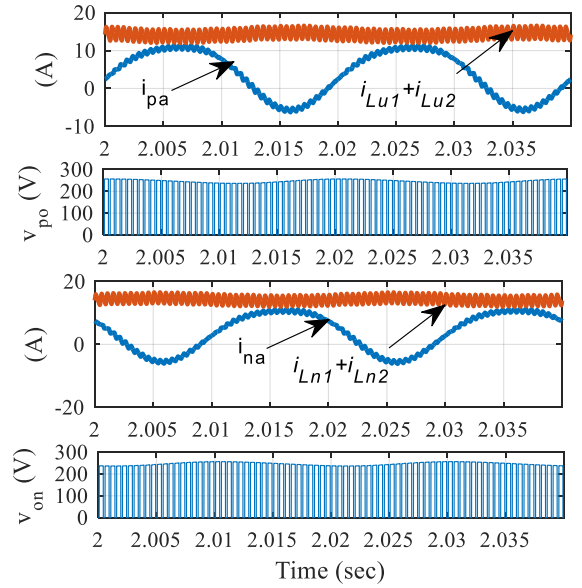

(a)
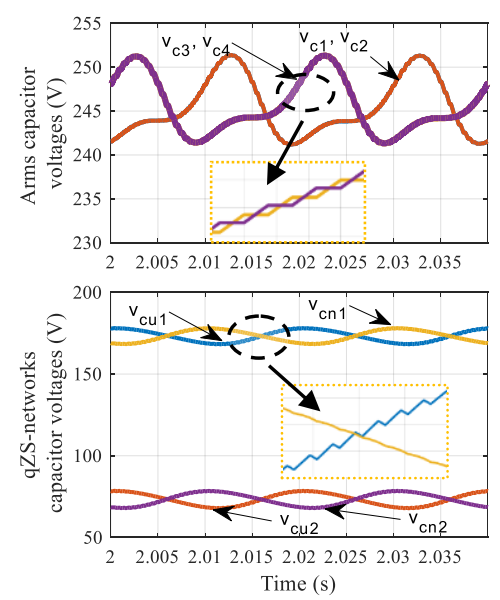

(b)

\begin{tabular}{lclc}
\multicolumn{4}{c}{ TABLE 1: ZSI SIMULATION MODEL PARAMETERS } \\
\hline Source voltage E & $200 \mathrm{~V}$ & $\begin{array}{l}\text { Load inductance } \\
\text { and resistance }\end{array}$ & $\begin{array}{c}10 \mathrm{mH}, \\
10 \Omega\end{array}$ \\
\hline $\begin{array}{l}\text { qZS-networks } \\
\text { inductances }\end{array}$ & $10 \mathrm{mH}$ & $\begin{array}{l}\text { qZS-networks } \\
\text { Capacitances }\end{array}$ & $3.3 \mathrm{mF}$ \\
\hline MMC-arm inductance & $4 \mathrm{mH}$ & $\begin{array}{l}\text { MMC-arm } \\
\text { capacitances }\end{array}$ & $1.5 \mathrm{mF}$ \\
\hline Switching frequency & $2 \mathrm{kHz}$ & Output frequency & $50 \mathrm{~Hz}$
\end{tabular}

detailed previously. The load voltage and current and their harmonic spectrums for both proposed topologies are shown in Fig. 7c and Fig. 8c respectively. The two topologies achieve approximately equal amplitude of fundamental voltage $(173 \mathrm{~V}$ at $M=0.7$ ). By setting $M$ to one at a source voltage of $200 \mathrm{~V}$, the obtained peak value of the fundamental voltage using the proposed converter will be $247 \mathrm{~V}$ at $d_{s h}=0.3$, which is higher than $100 \mathrm{~V}$ (one half of the source voltage) that could be obtained from a traditional MMC without qZS-network. As is clear from Fig. 7c and Fig. 8c, the BqZS-MMC has lower low order harmonics $\left(3^{\text {rd }}, 5^{\text {th }}\right.$ and $\left.7^{\text {th }}\right)$ and also a slightly lower total harmonic distortion (THD) compared to qZS-MMC.

It can be concluded that the simulation results shown in Figs. 6 to 8 are consistent with the theoretical analysis presented in this paper and that the proposed BqZS-MMC performs better than qZS-MMC with a wide range of $M$, e.g. for a $\mathrm{PF}=0.95$ that has been employed in this study, the maximum value for $M$ is 0.74 for qZS-MMC while BqZSMMC can operate at higher values.

\section{VIII.CONCLUSION}

This paper proposed a novel bidirectional quasi Z-source modular multilevel converter topology that is able to achieve buck and boost voltage capabilities. This converter combines the advantages of both qZS circuit and MMC. An analytical model of the converter has been derived that revealed the limitations of the converter. The models of the proposed configurations were verified by simulation at different modulation indexes in boost mode. The simulation results showed that BqZS-MMC overcomes the weaknesses related to the qZS-MMC such as, eliminating DC-link voltage drops, better output voltage and current harmonic spectrums and avoiding overcharging the converter capacitors.

Fig. 6: Simulation results of the proposed BqZS-MMC with M=0.7 and $d_{s h}=0.3$ (a) Upper and lower arms currents and DC-link voltages (b) Arms and qZSnetwork capacitors voltages (c) Load voltage and current and harmonics spectrum. 

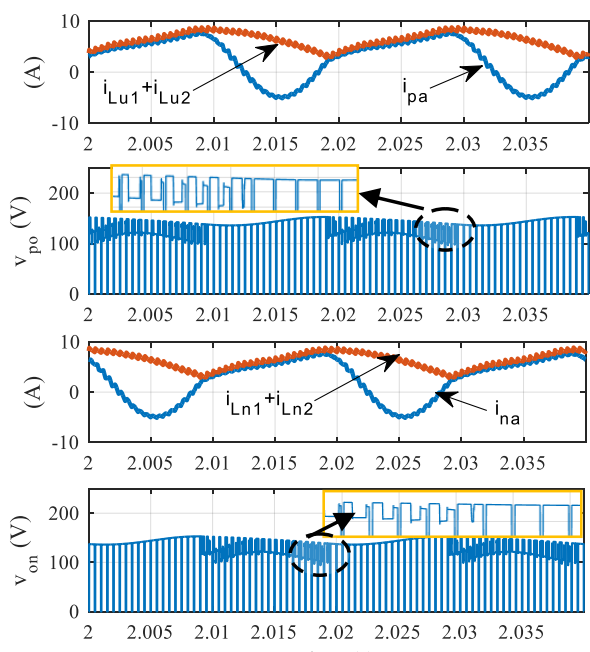

Time (s)

(a)
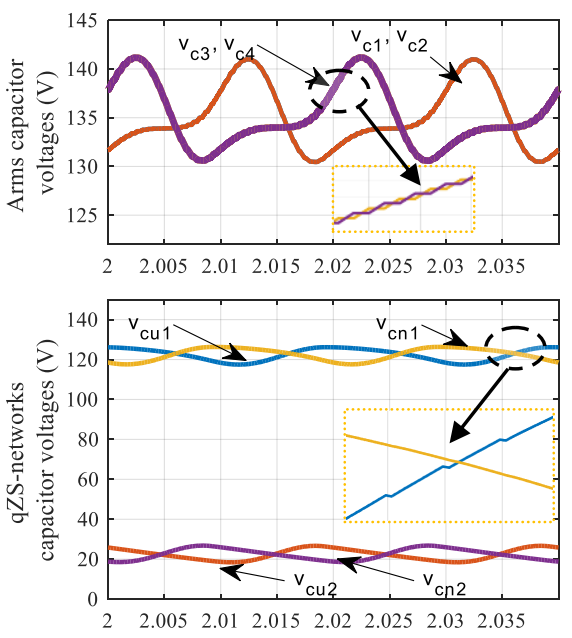

Time (s)

(b)
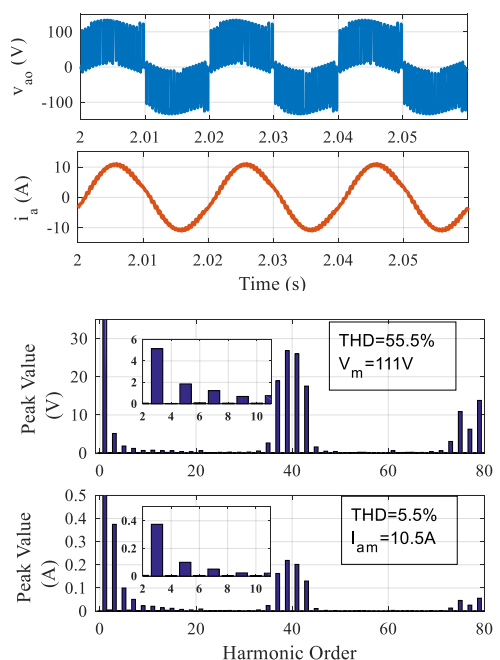

(c)

Fig. 7: Simulation results of the proposed qZS-MMC with $\mathrm{M}=0.9$ and $d_{s h}=0.1$ (a) Upper and lower arms currents and DC-link voltages (b) Arms and qZSnetwork capacitors voltages (c) Load voltage and current and harmonics spectrum.
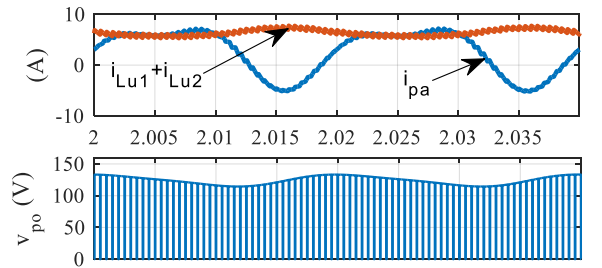

$\begin{array}{llllllll}2 & 2.005 & 2.01 & 2.015 & 2.02 & 2.025 & 2.03 & 2.035\end{array}$
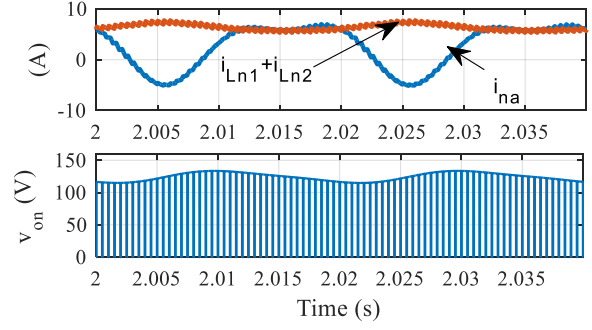

(a)
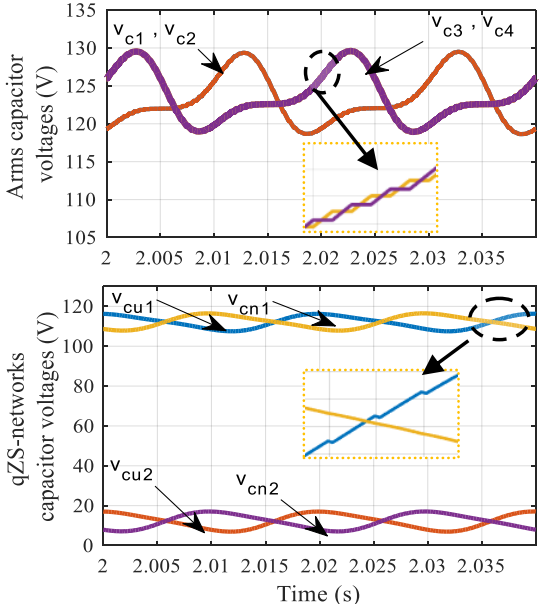

(b)
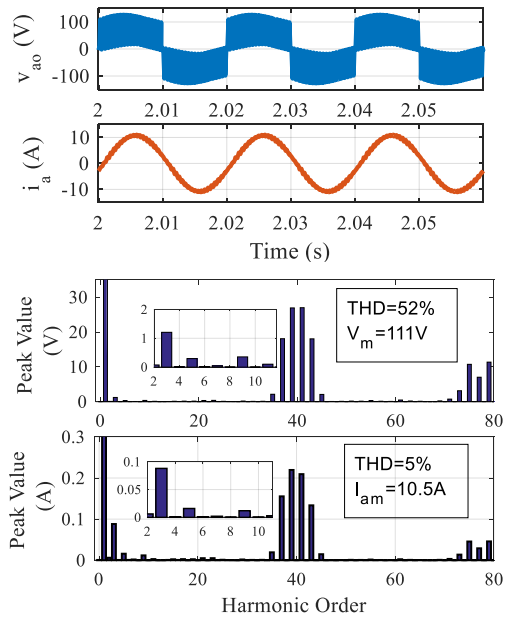

(c)

Fig. 8: Simulation results of the proposed BqZS-MMC with M=0.9 and $d_{s h}=0.1$ (a) Upper and lower arms currents and DC-link voltages (b) Arms and qZSnetwork capacitors voltages (c) Load voltage and current and harmonics spectrum.

\section{REFERENCES}

[1] M. Monadi, C. Koch-Ciobotaru, A. Luna, J. I. Candela, and P. Rodriguez, "Multi-terminal medium voltage DC grids fault location and isolation," IET Generation, Transmission \& Distribution, vol. 10, pp. 3517-3528, 2016.

[2] M. Stieneker and R. W. D. Doncker, "Medium-voltage DC distribution grids in urban areas," in 2016 IEEE 7th International Symposium on Power Electronics for Distributed Generation Systems (PEDG), 2016, pp. $1-7$.

[3] A. Hinz, M. Stieneker, and R. W. D. Doncker, "Impact and opportunities of medium-voltage DC grids in urban railway systems," in 2016 18th European Conference on Power Electronics and Applications (EPE'16 ECCE Europe), 2016, pp. 1-10.

[4] H. Abu-Rub, J. Holtz, J. Rodriguez, and G. Baoming, "Medium-Voltage Multilevel Converters-State of the Art, Challenges, and Requirements in Industrial Applications," IEEE Transactions on Industrial Electronics, vol. 57, pp. 2581-2596, 2010.

[5] A. Lesnicar and R. Marquardt, "An innovative modular multilevel converter topology suitable for a wide power range," in 2003 IEEE Bologna Power Tech Conference Proceedings, 2003, p. 6 pp. Vol.3.

[6] S. Debnath, J. Qin, B. Bahrani, M. Saeedifard, and P. Barbosa, "Operation, Control, and Applications of the Modular Multilevel
Converter: A Review," IEEE Transactions on Power Electronics, vol. 30, pp. 37-53, 2015.

[7] M. Saeedifard and R. Iravani, "Dynamic performance of a modular multilevel back-to-back HVDC system," in 2011 IEEE Power and Energy Society General Meeting, 2011, pp. 1-1.

[8] A. U. Lawan, H. Abbas, J. G. Khor, and A. A. Karim, "Dynamic performance improvement of MMC inverter with STATCOM capability interfacing PMSG wind turbines with grid," in 2015 IEEE Conference on Energy Conversion (CENCON), 2015, pp. 492-497.

[9] O. Ellabban and H. Abu-Rub, "Z-Source Inverter: Topology Improvements Review," IEEE Industrial Electronics Magazine, vol. 10, pp. 6-24, 2016.

[10] J. Anderson and F. Z. Peng, "A Class of Quasi-Z-Source Inverters," in 2008 IEEE Industry Applications Society Annual Meeting, 2008, pp. 17.

[11] F. Z. Peng, "Z-source inverter," in Conference Record of the 2002 IEEE Industry Applications Conference. 37th IAS Annual Meeting (Cat. No.02CH37344), 2002, pp. 775-781 vol.2.

[12] G. P. Adam, O. Anaya-Lara, G. M. Burt, D. Telford, B. W. Williams, and J. R. Mcdonald, "Modular multilevel inverter: Pulse width modulation and capacitor balancing technique," IET Power Electronics, vol. 3, pp. 702-715, 2010. 